Article

\title{
The Performance of the Smart Cities in China-A Comparative Study by Means of Self-Organizing Maps and Social Networks Analysis
}

\section{Dong Lu ${ }^{1}$, Ye Tian ${ }^{2}$, Vincent Y. Liu ${ }^{3, *}$ and Yi Zhang ${ }^{4}$}

1 School of Business, Sichuan Normal University, Chengdu 610101, China;

E-Mail: dlu@sicnu.edu.cn

2 School of Economics and Management, Southwest Jiaotong University, Chengdu 610031, China;

E-Mail: ye.tian@my.swjtu.edu.cn

3 School of Business, Macau University of Science and Technology, Taipa, Macau

4 Department of Mathematics, Tongji University, Shanghai 200092, China;

E-Mail: 08zhangyi@tongji.edu.cn

* Author to whom correspondence should be addressed; E-Mail: ydliu@ must.edu.mo;

Tel.: +853-8897-2862.

Academic Editor: Marc A. Rosen

Received: 3 November 2014 / Accepted: 2 June 2015 / Published: 12 June 2015

\begin{abstract}
Smart cities link the city services, citizens, resource and infrastructures together and form the heart of the modern society. As a "smart" ecosystem, smart cities focus on sustainable growth, efficiency, productivity and environmentally friendly development. By comparing with the European Union, North America and other countries, smart cities in China are still in the preliminary stage. This study offers a comparative analysis of ten smart cities in China on the basis of an extensive database covering two time periods: 2005-2007 and 2008-2010. The unsupervised computational neural network self-organizing map (SOM) analysis is adopted to map out the various cities based on their performance. The demonstration effect and mutual influences between these ten smart cities are also discussed by using social network analysis. Based on the smart city performance and cluster network, current problems for smart city development in China were pointed out. Future research directions for smart city research are discussed at the end this paper.
\end{abstract}

Keywords: smart cities; social network analysis; self-organizing map 


\section{Introduction}

As a system of systems, modern cities link the city services, citizens, energy system, water system, communication system, transport system and business together by providing the location and stimulus for learning, creative thinking, entrepreneurial spirit, socio-economic progress, new technologies development and ecologically sustainable transformation [1,2]. With the development of modern technology in everyday urban life, cities are increasingly moving from "sense of place" - a collection of static infrastructures - to a "place of senses"- a dynamic and evolving smart ecosystem known as digital cities, intelligent cities, high-tech district, virtual cities, information cities, wired cities, creative cities and knowledge-based cities [3-8]. To distinguish with these concepts, the idea of "smart city" has appeared and become fashionable currently.

As a city development strategy, smart cities rely on key technologies, such as modern transport technologies and the necessary policy framework or smart governance, e.g., "e-governance" or "e-democracy" [9-11]. Moreover, other technology aspects of smart cities, including security/safety, green, efficient and sustainable energy, also need to be considered [12,13]. Belissent defined a smart city as a city that "uses information and communications technologies to make the critical infrastructure components and services of a city more aware, interactive and efficient" [14]. Therefore, modern technologies, especially wireless sensor networks (WSNs), offer a broad number of services for smart cities, including the Internet of Things, intelligent buildings and homes, water/electricity distribution systems, environmental monitoring, intelligent transportation systems, health care and other applications [15-17]. Information and communications technology (ICT) has become a key technology foundation in creating more instrumented and interconnected urban environments [18]. Komninos described the relation between technology and smart cities by listing four main components of smart cities, which includes the application of a wide range of electronic and digital technologies to communities/cities, the use of information technologies to transform life and work within a region, the embedding of such ICTs in the city and the mechanism to bring ICTs and people together [5,19]. Compared with digital city or intelligent city, the main focus of smart city is not limited to ICT infrastructure but also on sustainable growth, efficiency, productivity, competitiveness, education/human capital, social and relational capital, and environmental interest [4]. Smart cities are moving from simple city websites in 1990s (digital cities) to knowledge management and library with humanistic concern nowadays [19].

In Europe, the smart city is a policy that is designed to transfer cities into innovation hubs in order to strengthen the socio-economic progress in EU. The European Commission focuses on high efficient and clean technology and the "smart city policy" in Europe is related with energy efficiency, renewable energy and green mobility [20]. Besides, projects such as "WISEBED" or "Smart Santander" propose architectures of communications and related services for smart cities [17,21,22]. Smart cities in Europe also emphasize human capital, including highly educated people, knowledge-intensive jobs, output-oriented planning systems, creative activities and sustainability-oriented initiatives [3,10,23-27].

In North America, city development strategies focus on smart growth-sustainable urban development. According to the definition by Smart Growth BC (2007), smart growth means "a collection of land use and development principles that aim to enhance our quality of life, preserve the natural environment, and save money over time. Smart growth principles ensure that growth is fiscally, environmentally and socially responsible and recognizes the connections between development and 
quality of life" [28]. The smart growth strategy has been successfully applied in the urban zoning and urban design in Vancouver [29]. The downtown core of Toronto also adopted the smart growth strategy and developed a "livable" and vibrant residential and commercial area [28]. Many cities in the U.S., such as Seattle, Washington; Portland, Oregon; San Francisco, San Jose, Santa Monica, Santa Barbara, Los Angeles, and Sacramento, California; and many others have begun to focus on sustainability development, including sustainable economic development and increasing population densities in the urban centers $[28,30]$.

Smart cities in Asia focus on the adoption of advanced technology. Because of the land constraint, Singapore developed supporting technologies to meet the mobility needs of people, e.g., smart control, monitoring and enforcement systems for transportation [31]. These technological systems could also achieve a sustainability target (the safe, efficient and sustainable transport system) by reducing human involvement [31]. Similar to Singapore, cities in Japan also focus on public transportation and communication technologies. The land use and adaptive suburbia issues in Japan are also key components of the smart city policy [11,32]. A national strategic development project-u-City (ubiquitous computing city) was launched in Korea, which tries to improve quality of life in the cities through ubiquitous ICT services supported by both the public and private sectors [33]. The goal of u-City was to integrate advanced ICT-based infrastructures and ubiquitous information services into the urban space, based on which the high quality of life, including security, welfare, convenience, and well managed city environment could be provided for residents [32,33]. Song-do City in Korea could be seen as one of Asia's most-advanced Digital City projects [33].

In summary, the development routes of the above smart cities are different and each with their own strengths, which could serve as valuable references for the cities in developing countries. Besides, these early-developed cities also provide the demonstration effects to their neighbor cities. It is worth mentioning that smart city cluster networks also appeared in different areas: smart cities in USA and Canada influence each other and form the largest cluster network in the world. Smart cities in Britain, Japan, and Australia also lead the development trends in surrounding areas. The formation of the cluster networks provides new impetus to the development of smart cities.

In China, the original concept of smart city could trace back to "digital city", which becomes a fashion label among many mainland cities after 2000. By that time, the digital cities focused on making policies to encourage the high-tech industry. In 2006, the National Administration of Surveying, Mapping and Geo-information launched the "digital city and the geo-information framework" project to develop public platform of geo-information in different cities. Jiangxing, Qianjiang, Taiyuan, Weihai, Deyang, etc. have finished the project and adopted the platform to support urban planning, environment, public security, business, public health and tourism. In 2013, the Ministry of Housing in China published a pilot smart city list, which includes 37 cities, 50 districts/counties and three towns [34]. One year later, 100 more areas were selected for the list [34]. The planning policies from the Central Government of China play a leading role during its smart city development process.

By comparing with other cities around the world, smart cities in China are still in the preliminary stage. The increasing global development trend of smart cities leads to the need to map out the develop route of the cities in China. A benchmarking of these cities will also be needed to serve as development and governance experiences for other cities. Different with other countries, the smart city development relies on the significant demonstration effect in China due to the strong guidance from the Central 
Government. Similar to other National Development Plans, the Chinese government would like to select and invest in pilot cities, such as Beijing and Shanghai, to lead smart city development within the whole country. This top-down driven process makes the formation of smart city cluster network in China different with other areas - policy learning and related mutual influences are common between different cities. Therefore, a deep discussion on the mutual influences and demonstration effects of different cities will be needed to understand the cluster network in China, which could help to identify the strengths and weaknesses of these cities.

\section{Smart City Benchmarking}

One study on the performance evaluation of smart cities is that out Caragliu et al. [13]. The authors analyzed and ranked smart cities in Europe through infrastructural, human and social capital factors, which include information on demography, social aspects, economic impacts, training and education, environmental, culture and recreation. The data source is from EU Urban Audit database. A triple helix model was proposed to measure the performance of smart cities. Within the model, there are many indicators, including lighting, citizen information management, integrated urban energy planning and management, and ICT-based solutions for new urban design and management [13]. The authors discussed the relations between smart city components, visions, and strategies.

Followed by this research, Caragliu et al. adopted the "urban smartness" indicator to assess 94 cities within the European Union [35]. Different from previous work, this research focused on human capital, density, industrial mix, amenities and attractiveness. The authors discussed the policy impact of this smartness indicator by identifying the impacts of smartness on urban performance and wealth [35]. At the end of the research, the authors made suggestions on further investment in smart urban attributes for different cities [35].

Méndez et al. reported on a comparative analysis of the 363 Spanish cities that had over 20,000 inhabitants in 2006 [36]. The authors used a knowledge indicator database and defined a typology based on principal components factor analysis and cluster analysis [36]. Kourtit et al. offered a comparative analysis of nine European smart cities covering two time periods: 1999-2002 and 2003-2006 [3]. Therefore, the roadmap of nine cities could be found. The authors conducted a principal component analysis to create a smart city indicator, which includes employment, ICT, population, e-government, local government, infrastructure, etc. [3]. The authors also adopted a new approach-self-organizing map analysis - to position the various cities. Mattoni et al. provides a holistic and specific approach to access the renovation and design of smart cities, which can be seen as a unique analysis perspective [28]. The approach was based on matrices of integration, which can be used for investigating the relations existing among urban and territorial networks, actors and stakeholders, functions and activities, etc. [37].

According to the above analysis, there are numerous attempts to rank the performance of cities in the world nowadays. These papers provide valuable suggestions on both academia and industry. However, the previous benchmarking studies discussed the smart city cluster issues by using the results of different indicators only, which ignored the mutual influences between different cities. This data-processing approach was widely adopted by previous scholars because the demonstration effect between different cities of other countries is not as strong as the cities in China due to the inexistence of a significant top-down driven policy or guidance. The present study follows the previous studies and tries to find out the 
positions of different smart cities in China from a broad multidimensional perspective by using self-organizing map (SOM) analysis. Beyond this, this research also focuses on finding the mutual influences between different smart cities, which will show the result of the demonstration effect by using social network analysis. This research plans to map out the relative differences on the "smartness" of selected smart cities in China and their developing model. The application of the SOM allows us to display the information in an intuitive way and enhances the understanding of the changes that have occurred year by year. Social network analysis can help us to understand the characteristics of smart city cluster network in China. This research also seeks to provide an operational analytical framework for characterizing smart cities in China and offer a more truthful and realistic representation for supporting policy-making and highlight the need for geographical policy actions.

\section{Methodology and Database}

\subsection{SOM}

Self-organizing map (SOM) network is a variation of neural computing network. It was developed in the context of the study of the spatial organization of brain functions [2,38,39]. It allows researchers to explore large and highly dimensional datasets by transferring the dataset into a lower dimensional (usually one- or two-dimensional) output map while maintaining the original topological relations and, thus, enables decision maker to visualize the relationships among the input datasets [40,41].

The SOM is an unsupervised computational neural network. During the SOM training process, the input data compete to influence the neurons, which are arranged on a regular lattice and interconnected to each other to form the neural network [42]. The input observations of the network are not categorized a priori, but rather the structure is unknown, hence "unsupervised" [40]. After training, the SOM provides a surface where each neuron models a portion of that space. The surface could map statistical observations with highly informative and intuitive visualizations [42].

The input vector $t$ could be expressed as:

$$
\mathrm{x}=\left[\varepsilon_{1}(\mathrm{t}), \varepsilon_{2}(\mathrm{t}), \cdots \varepsilon_{n}(\mathrm{t})\right]^{T} \in R^{n}
$$

where $\varepsilon_{i}(\mathrm{t})$ represents the value for each dimension. The $\mathrm{n}$-dimensional vectors will be clustered in a low (usually two) dimensional dataset, the output space. Depending on the distribution of the dimensions and their scales (if they represent different variables), it may be useful to normalize them, so that they all range within the same bounds and/or take a logarithmic Each of the nodes of the output space is assigned a parametric real vector and it could be expressed as follows:

$$
\mathrm{m}_{i}=\left[\mu_{i n}, \mu_{i n}, \cdots \mu_{i n}\right]^{T} \in R^{n}
$$

The values of $\mathrm{m}_{i}$ could be chosen randomly, or assigned with previous data to speed up the computing process [3]. This is defined as any distance metric between two vectors $x$ and $\mathrm{m}_{i}$. During the training process, each $d\left(x, m_{i}\right)$ signal vector is sequentially presented to the output space to form the best matching unit (BMU). The BUM for $x$ is defined as:

$$
\mathrm{c}=\arg \min _{\mathrm{i}}\left\{d\left(x, m_{i}\right)\right\}
$$


The neuron $m_{i}$ is activated after BMU $c$ is found. During the adaptive process, $c$ and its topological neighbors are modified by the following scheme:

$$
m_{i}(t+1)=m_{i}(t)+h_{c i}(t)\left[x(t)-m_{i}(t)\right]
$$

where $t$ and $t+1$ represent the initial state and the final state respectively; $h_{c i}(t)$ represents a neighborhood function to describe how the BMU and its neighbors are modified when activated by a signal. Once the training stage is completed, there are two approaches for exploring the information provided by a trained SOM [3]: the first one is to compare the network created with the original input vectors; the second one is to link the original data on the network using the BMUs for each vector.

The SOM has been successfully applied as a classification tool to various problem domains, including speech recognition, image data compression, image or character recognition, robot control, medical diagnosis, and demography [43-47].

Recently, the SOM has been applied in the spatial and social sciences, e.g., urban sprawl [41], market segmentation [47] corporate finance [48,49], published research [50] and material deprivation research [51,52]. The SOM showed promising results as compared to the traditional statistical approaches. The benefits of SOM includes: exploring the structures and uncovering hidden patterns of large and highly dimensional data-sets about socio-economic characteristics, making no assumptions about the underlying population distribution of the dataset, presenting the visualization of data and the complex entities in an understandable way $[41,42]$.

\subsection{Social Network Analysis}

The first step for social network analysis is to establish a matrix, which includes the all the indicators with different periods of each selected city. It is assumed that random vectors $U$ and $V$ satisfy the following relations, $\varepsilon$ represents the error:

$$
U=\lambda V+b+\epsilon
$$

The next step is to conduct a least squares analysis. There are k observation values (indicators) belonging to $U$ and $V: U^{\alpha}=\left(u_{1}^{\alpha}, \cdots, u_{n}^{\alpha}\right), V^{\alpha}=\left(v_{1}^{\alpha}, \cdots, v_{n 1}^{\alpha}\right), \alpha=1, \cdots \mathrm{k}$. Then the optimal values of $\lambda$ and $\mathrm{b}=\left(b_{1}, \cdots, b_{n}\right)$ are required to find to minimize the error accumulative total:

$$
\begin{aligned}
F\left(\lambda, b_{1}, \cdots, b_{n}\right) & \\
& =\sum_{\substack{\alpha=1 \\
k}}^{k}\left(u_{1}^{\alpha}-\lambda v_{1}^{\alpha}-b_{1}\right)^{2} \\
& +\sum_{\alpha=1}^{k}\left(u_{2}^{\alpha}-\lambda v_{2}^{\alpha}-b_{2}\right)^{2}+\cdots+\sum_{\alpha=1}^{k}\left(u_{n}^{\alpha}-\lambda v_{n}^{\alpha}-b_{n}\right)^{2}
\end{aligned}
$$

According to the necessary condition of minimum value in calculus, we can list the following $\mathrm{n}+1$ equations: 


$$
\begin{gathered}
\frac{\partial F}{\partial \lambda}=2\left(-\sum_{i=1}^{n} \sum_{\alpha=1}^{k} u_{\alpha}^{i} v_{\alpha}^{i}+\lambda \sum_{i=1}^{n} \sum_{\alpha=1}^{k}\left(v_{\alpha}^{i}\right)^{2}+b_{1} \sum_{\alpha=1}^{k} v_{1}^{\alpha}+\cdots+b_{n} \sum_{\alpha=1}^{k} v_{n}^{\alpha}\right)=0 \\
\frac{\partial F}{\partial b_{1}}=2\left(-\sum_{\alpha=1}^{k} u_{1}^{\alpha}+\lambda \sum_{\alpha=1}^{k} v_{1}^{\alpha}+k b_{1}\right)=0 \\
\frac{\partial F}{\partial b_{n}}=2\left(-\sum_{\alpha=1}^{k} u_{n}^{\alpha}+\lambda \sum_{\alpha=1}^{k} v_{n}^{\alpha}+k b_{n}\right)=0 \\
\lambda\left(\begin{array}{c}
\lambda \sum_{i=1}^{n} \sum_{\alpha=1}^{k}\left(v_{\alpha}^{i}\right)^{2}+b_{1} \sum_{\alpha=1}^{k} v_{1}^{\alpha}+\cdots+b_{n} \sum_{\alpha=1}^{k} v_{n}^{\alpha}=\sum_{i=1}^{n} \sum_{\alpha=1}^{k} u_{\alpha}^{i} v_{\alpha}^{i} \\
\lambda b_{1}=\sum_{\alpha=1}^{k} u_{1}^{\alpha} \\
\lambda \sum_{\alpha=1}^{k} v_{n}^{\alpha}+k b_{n}=\sum_{\alpha=1}^{k} u_{n}^{\alpha}
\end{array}\right.
\end{gathered}
$$

These equations can be written as $A b^{\prime}=w^{\prime}$, where

$$
A=\left(\begin{array}{cccc}
\sum_{i=1}^{n} \sum_{\alpha=1}^{k}\left(v_{\alpha}^{i}\right)^{2} & \sum_{\alpha=1}^{k} v_{1}^{\alpha} & & \\
\sum_{\alpha=1}^{k} v_{1}^{\alpha} & k & \ldots & 0 \\
\vdots & \vdots & & \\
\sum_{\alpha=1}^{k} v_{n}^{\alpha} & 0 & & \\
b^{\prime}=\left(\lambda, b_{1}, \ldots, b_{n}\right)^{T} & & \\
w^{\prime}=\left(\sum_{i=1}^{n} \sum_{\alpha=1}^{k} u_{\alpha}^{i} v_{\alpha}^{i}, \sum_{\alpha=1}^{k} u_{1}^{\alpha}, \ldots, \sum_{\alpha=1}^{k} u_{n}^{\alpha}\right)
\end{array}\right.
$$

As $A$ and $w^{\prime}$ can be calculated by the sample data, then we can get $\lambda$ by solving $b^{\prime}=A^{-1} w^{\prime}$. $\lambda$ represents the influence of $\mathrm{V}$ on $\mathrm{U}$.

This method can be used for compare the different developing stages of selected smart cities and show the mutual influences between these cities.

\subsection{Database and Indicators}

It has become fashionable to design rankings of cities from different angles, e.g., accessibility, wealth, business climate, etc. [4]. In our empirical work, we have collected a data set with a wealth of information on factors related to the characteristics of smart cities' performance from the Yearbook of Chinese Cities [53]. This smart cities group are selected from two lists, one is the pilot smart city list provided by the Ministry of Housing as we mentioned earlier, the other is smart city evaluation report supported by the Ministry of 
Industry and Information Technology [54]. The common cities within the two reports were picked up as the sample in this research (Table 1). The research seeks to map out smart cities' performances over three years at two points in time: the first period is from 2005-2007, and the second period is from 2008-2010.

Table 1. Ten smart cities in China.

\begin{tabular}{cc}
\hline \multicolumn{2}{c}{ Ten smart cities in China } \\
\hline Wuhan & Chengdu \\
Shanghai & Hangzhou \\
Beijing & Wuxi \\
Dalian & Guangzhou \\
Tianjin & Shenzhen \\
\hline
\end{tabular}

In order to position the smart cities and present the cluster network, it is important to identify "smartness" indicators, which should focus on a broad range of the "smartness" features. However, there is no common definition of the "smart cities" concept. Previous researchers provided multiple and different meanings: Zapater et al. thought that smart cities should perform well on six characteristics: economy, people, governance, mobility, environment and living [16]. Lombardi agreed that smart cities should be "smart" in economy, mobility, environment, people, living and smart governance [4]. Kourtit et al. discussed Smart Cities in Europe from multiple domains: demography, social aspects, economy, civic involvement, education, environment, transport, information society and culture [3]. Allwinkle et al. mentioned the IBM typology of urban issues for the smart city, including city services, citizens, transport, communication, water, business and energy [19]. Chourabi et al. identified eight factors of smart cities: management and organization, technology, governance, policy context, people and communities, economy, built infrastructure, and natural environment [55]. According to these studies, five common dimensions of smart cites could be found. These are communication, business, human capital, environment and public services. In this research, the ten selected cities will be analyzed based on the five dimensions. However, a deep discussion on the detail indicators within each dimension is needed, as smart cities in China are driven by government investment and policy guidance. Some smart city indicators, such as transparent governance, participation in decision - making, entrepreneurship, etc., could hardly be used in this research as the lack of source data. Therefore, this study seeks to map out smart cities in China by the following indicators with public data from the selected local governments:

- Communication: The validity of any city's claim to be smart has to be based on information and communication technologies (ICTs) [39]. Smart city forerunners such as San Diego, San Francisco, Ottawa, Brisbane, Amsterdam, Kyoto, and Bangalore are famous for their communication infrastructure, such as mobile technologies, connected devices and network platforms [19]. In this research, two indicators-Internet users (households) and Mobile phone users (households) - are adopted. Some local governments in China started to apply e-government or e-democracy by discussing with the public through social network services. However, this communication function is not applied by all the select smart cities in this research. Besides, some online discussion platforms could not get sufficient public engagement due to the limitations on 
discussion topics. Therefore, the e-government or e-democracy indicator will not be considered in this research.

- Business: Smart cities do not seek for economic growth only. However, it is undeniable that sustainable economic growth and knowledge-based industries are two major components of smart cities $[13,38]$. We use the per capita GDP and the proportion of GDP tertiary industry account for to measure the business factor of the selected cities. The per capita GDP is selected in this research as the general GDP does not reflect the public benefit. The proportion of GDP tertiary industry accounts for was selected as the tertiary industry (service industry) could represent the business innovation capacity in China. The GDP of primary and secondary industry are not adopted in this research, as both of these industries are still in the extensive management stage in China. Besides, cities with a high proportion of primary or secondary industry, e.g., Anshan, could not be selected into smart city groups because of the unfriendly living environment. Many cities in China have been operating for mining resources or developing key industries since the 1950s. The power of a factory owner within these cities could be larger than the mayor. However, these cities may lose vitality once they run out of nature resources.

- Human capital: Human capital issue, such as information consumption, life-long learning, cultural facilities, etc., is also a key component for smart cities [13,38]. A smart city should attract young, well-educated professionals and the city should be a sign of cultural activity and diversity [56]. The integrated knowledge-intensive activities provided by smart cities should encourage knowledge sharing and innovation [57]. In this research, the proportion of tertiary industry employment indicator is adopted for representing "knowledge". The Public Library Collection (per one hundred persons) indicator is also adopted to represent information consumption and lifelong learning. The Public Library Collection (per one hundred persons) indicator is a common one adopted by previous scholars $[4,13,35]$.

- Environment: Environmental issues are related to urban growth [28]. We are going to use the residential water consumption, the urban and rural residents electricity consumption and the per capita green area (square meters/person) to measure the environmental factor of smart cities in China, which are also adopted by former researchers $[3,35,36]$. The Pollution Index in China is not taken into account as its authority has been questioned.

- Public Service. The public service issues are selected in this research for two reasons: First, the e-government is a key component of smart cities. Second, a smarter city should manage natural resources, ICT infrastructures and other assets wisely by providing cross-agency visibility of planned interventions [26]. Three factors: Financial investment in science (ten thousand yuan); Per urban capita road area (square meters); and Financial investment in education (ten thousand yuan) are adopted in the research. Table 2 lists all the indicators of the five dimensions. 
Table 2. The indicators for smart city evaluation.

\begin{tabular}{|c|c|}
\hline Dimensions & Indicators \\
\hline \multirow{2}{*}{ Communication } & Internet users (households) \\
\hline & Mobile phone users (households) \\
\hline \multirow{2}{*}{ Business } & The proportion of GDP tertiary industry accounts for \\
\hline & The per capita GDP (yuan) \\
\hline \multirow{3}{*}{ Public service } & Financial investment in science (ten thousand yuan) \\
\hline & Per urban capita road area (square meters) \\
\hline & Financial investment in education (ten thousand yuan) \\
\hline \multirow{2}{*}{ Human capital } & The proportion of tertiary industry employment \\
\hline & Public Library Collection (Every one hundred people) \\
\hline \multirow{3}{*}{ Environment } & Residential water consumption (ton) \\
\hline & Urban and rural residents electricity consumption $(10,000 \mathrm{KWH})$ \\
\hline & Per capita green area (square meters / person) \\
\hline
\end{tabular}

\section{Patterns and Dynamics of Smart Cities in China: 2005-2010}

In this section, the ten selected cities will be mapped by the SOM approach in the two time periods: 2005-2007 and 2008-2010. Then, the features of smart city cluster network will be discussed by social network analysis. For the smart cities mapping, the evolution from 2005-2010 is translated into a movement from one location in the SOM to another one, which indicates the trajectories of the smart cities in China. The training parameters and other technical details for this SOM and the subsequent ones are reported here (Table 3 ).

Table 3. Technical parameters in the SOM analysis.

\begin{tabular}{cccc}
\hline \multicolumn{4}{c}{ SOM parameters in this research } \\
\hline Sigma Max & 10 & Learning Rate Min & 0.01 \\
Sigma Min & 2 & Iterations & 100 \\
Sigma Decreasing Rate & 0.1 & Number of X Neurons & 20 \\
Learning Rate Max & 0.1 & Number of Y Neurons & 20 \\
\hline
\end{tabular}

Figure 1 shows the cities' location from 2005-2007 (a) and the location from 2008-2010 (b). The SOM map is composed of many hexagon locations with different colors: from light to dark. The darker the color is, the higher position it is in the smart city ranking. By comparing Figures 1a and 1b, we observe a clear pattern: Wuhan, which in Figure 1a was located along the bottom edge, moves up to the top edge of Figure 1b, together with other cities, including Guangzhou, Shenzhen, etc. The other cities (Guangzhou, Shenzhen, etc.) remain in the same top right corner, experiencing no changes in their topology of location. In the most recent period (see Figure 1b), Beijing and Shanghai have been clearly ahead of other the cities during the three years' development. Thus, Beijing and Shanghai locate into a dark gray zone. Others, like Guangzhou, Shenzhen, etc. display low values in smartness, and thus may be found in the areas with lighter colors.

After finding out how the cities are mapped in the first and the second periods, the next step is to analyze the transitions over these periods and to discuss the dynamics of the process. Compared with Figure 1, which shows the cities' positions separately in each period, Figure 2 bridges both periods and 
shows the positions of the cities in different single years. The tool employed in this context is known as the trajectory [26], which is the length of different city positions at one point in time. Arribas-Bela et al. and Kourtit et al. adopted this tool to analyze the evolution of the cities over a period [2,3].

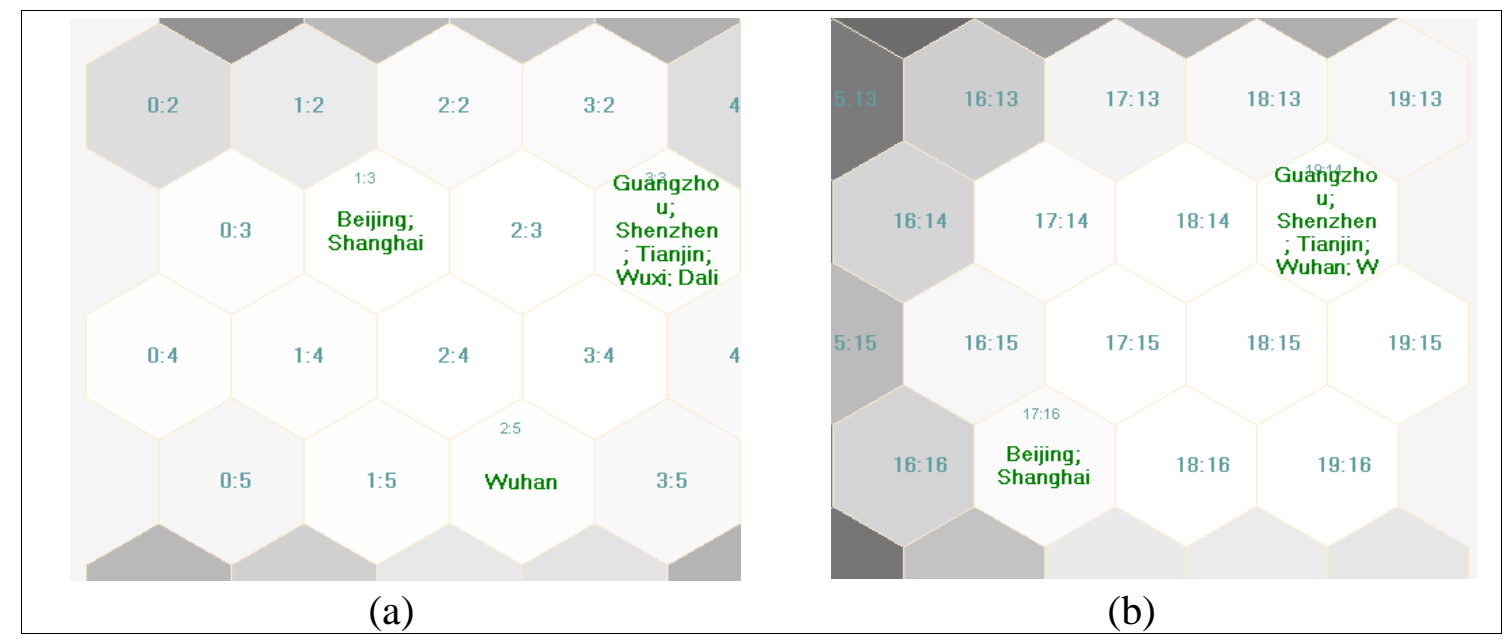

Figure 1. The smart cities' location from 2005-2007 (a) and the location from 2008-2010 (b).

Figure 2 and Table 4 show the trajectories by positioning the cities' location with the label of each year from 2005-2010. Each city was entered six times year by year. According to Figure 2, we could find that cities are concentrated in several hexagon locations, which is hard to add lines to for showing the movement. Therefore, Table 4 is created to present a clear result by showing positions of different cites by adding the year label, which indicates the trajectories. The first column in Table 4 shows different coordinates of the hexagon locations, as a result of SOM, each hexagon contains a unique coordinate, e.g., 2.5 indicates Wuhan in Figure 1a. The second column contains the city names with year label. According to the result, the longest trajectory belongs to Wuhan and shortest trajectory belongs to Wuxi. Shenzhen did not change much either. Most trajectories indicate that the cities do not "travel" more than five or six neurons - the hexagon locations - which means a slight evolution. Finally, it is also noticeable that most cities move together during 2005-2010. Dalian and Chengdu locate into a dark zone (high value). These movements across the SOM are based on all the selected variables, which is precisely why we employ a technique like the SOM, in order to reduce data sets of higher dimensions to two dimensions.

With the trajectories, it is also possible to link each city back to the different indicators in order to see the city behavior of particular dimensions (Figure 3). We did not conduct the analysis of individual indicator as the SOM looks for global patterns where all variables are considered that work best - the mechanisms of the SOM algorithm may be inaccurate in certain cases [3]. In Figure 3, it is easy to find that Beijing and Shanghai are always together and excel in public service - both of these cities locate in the darker hexagon zone. Guangdong joins the same group of Beijing and Shanghai in communication, business, human capital and environment. By extension, the planes are also very useful when comparing to the location of the cities (Figure 2): we can see how high scores cities in Figure 2, like Beijing or Shanghai, also have higher scores on public service - both of these cities locate in a dark gray zone, but not as well on all the other indicators. Shenzhen, Tianjin and Wuhan have a relatively high human capital performance. Dalian, Hangzhou and Chengdu appear to perform well in environment. 
Table 4. The trajectories the smart cities in China (2005-2010) with full cities' names.

\begin{tabular}{cl}
\hline Location & \multicolumn{1}{c}{ Cities and Year } \\
\hline $15: 8$ & Wuhan 2005 \\
$17: 8$ & Shanghai 2007 \\
$17: 9$ & Beijing 2007 \\
$14: 10$ & Shanghai 2008 \\
$16: 10$ & Shanghai 2009 \\
$18: 10$ & Dalian 2005; Beijing 2009; Beijing 2010 \\
$15: 11$ & Shanghai 2010 \\
$19: 11$ & Beijing 2006; Wuhan 2007 \\
$15: 12$ & Beijing 2008 \\
$17: 12$ & Tianjin 2005; Wuhan 2006 \\
$19: 12$ & Dalian 2006; Chengdu 2006 \\
$18: 13$ & Hangzhou 2005; Tianjin 2007; Hangzhou 2007; Chengdu 2007; Hangzhou 2008; \\
$19: 13$ & Chengdu 2008; Tianjin 2009; Hangzhou 2009 \\
$17: 14$ & Tianjin 2006; Hangzhou 2006 \\
& Wuxi 2006; Guangzhou 2007; Shenzhen 2007; Wuxi 2007; Dalian 2007; \\
$18: 14$ & Guangzhou 2008; Shenzhen 2008; Tianjin 2008; \\
19:14 & Chengdu 2005; Wuhan 2008; Tianjin 2010; Hangzhou 2010; Wuxi 2008; Dalian \\
& 2008; Guangzhou 2009; Shenzhen 2009; \\
18:15 & Wuhan 2009; Wuxi 2009; Dalian 2009; Chengdu 2009; Guangzhou 2010; \\
& Shenzhen 2010; Wuhan 2010; Wuxi 2010; \\
19:15 & Beijing 2005; Shanghai 2005; Guangzhou 2005; Shenzhen 2005; Wuxi 2005; \\
Shanghai 2006; Guangzhou 2006; Shenzhen 2006; \\
\hline
\end{tabular}

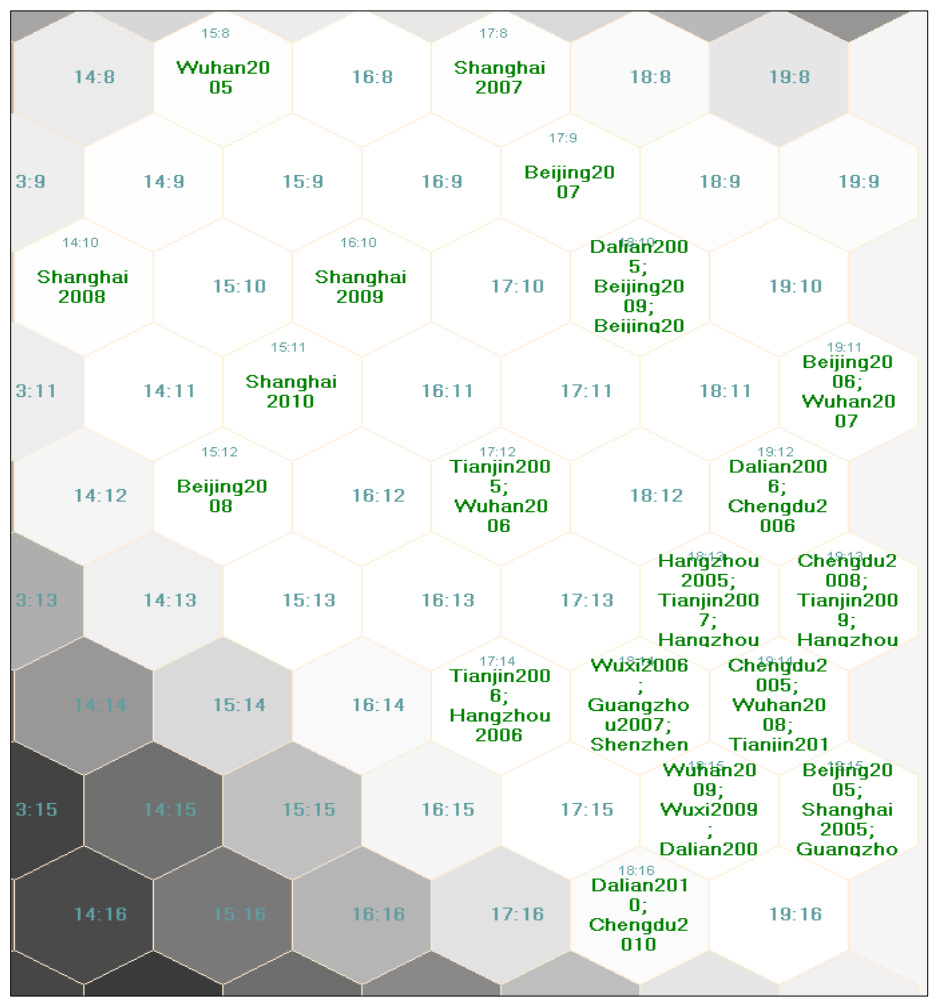

Figure 2. The trajectories the smart cities in China (2005-2010). 
It is worth noting that in Figure 3 there is no clear pattern that applies to all the indicators. There are some, such as the human capital and business, that show similar distributions but other indicators show a different pattern. This is a sign of the interrelations between the various indicators of the smart cities. It also highlights the need to consider different indicators by comparing Figures 1-3. From a policy-maker's perspective, place-based policies should be aimed at locally selected goals (e.g., increase in urban GDP or improving the environment).

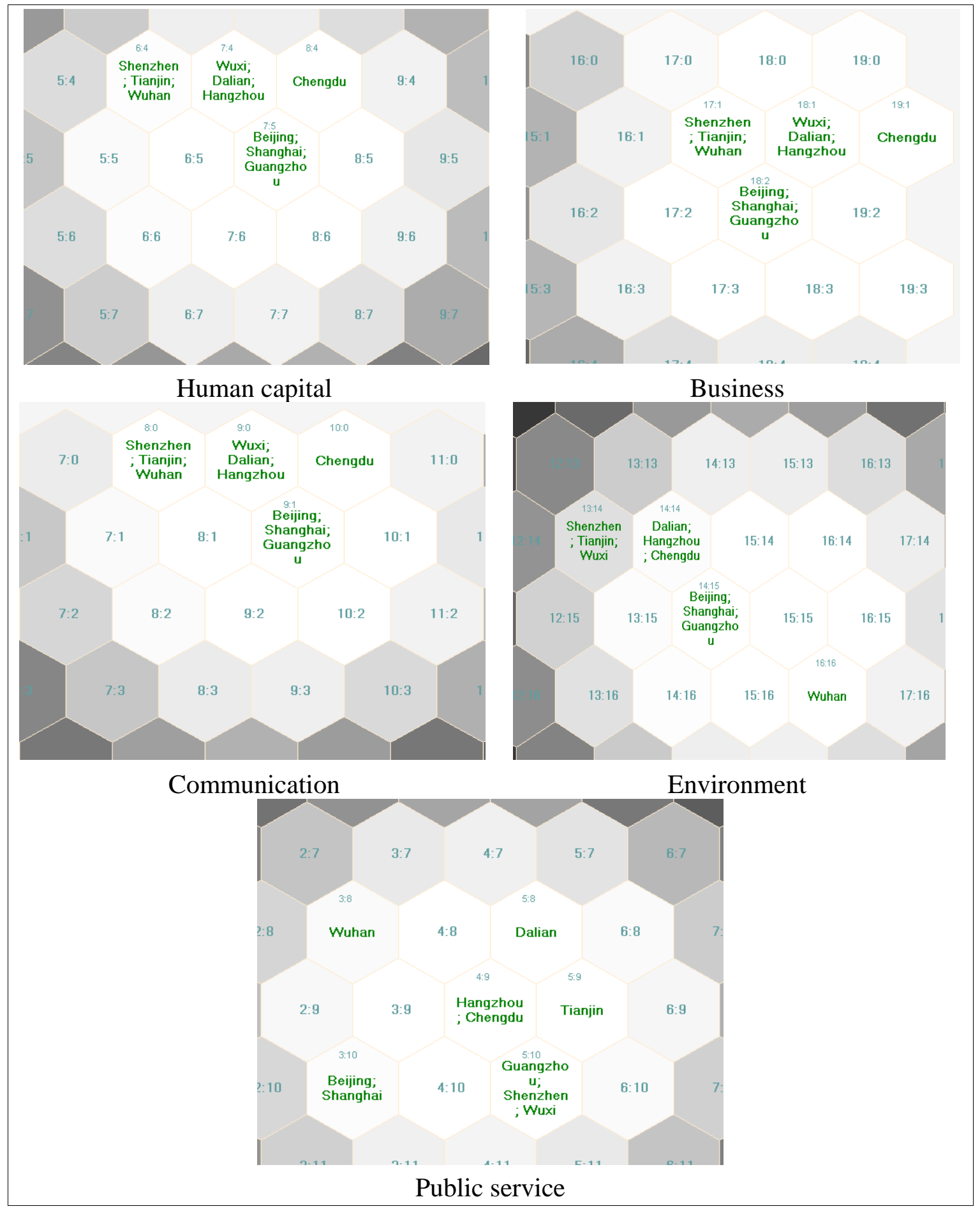

Figure 3. The city behavior of particular indicators. 
For the next step, the social network analysis is conducted based on the method described in Section 3.2. The subgroup analysis for smart city cluster during 2005-2007 and 2008-2010 are provided separately in Figures 4 and 5. Each figure contains three subgroups labeled by different colors. By comparing with the results from SOM (Figure 1), Beijing and Shanghai play leading roles, while the development model of the two cities are similar according to the subgroup analysis. Besides, the development models of other cities are also similar to Beijing or Shanghai, such as Chengdu. Shenzhen and Tianjin show their special features in smart city development. Dalian and Guangzhou moved together with Beijing during 2008-2010, which shows the strong demonstration effects of the Capital in China, as Dalian and Guangzhou belonged to different subgroups during 2005-2007. It can be found that more cities joined the Beijing and Shanghai group during 2005-2010.

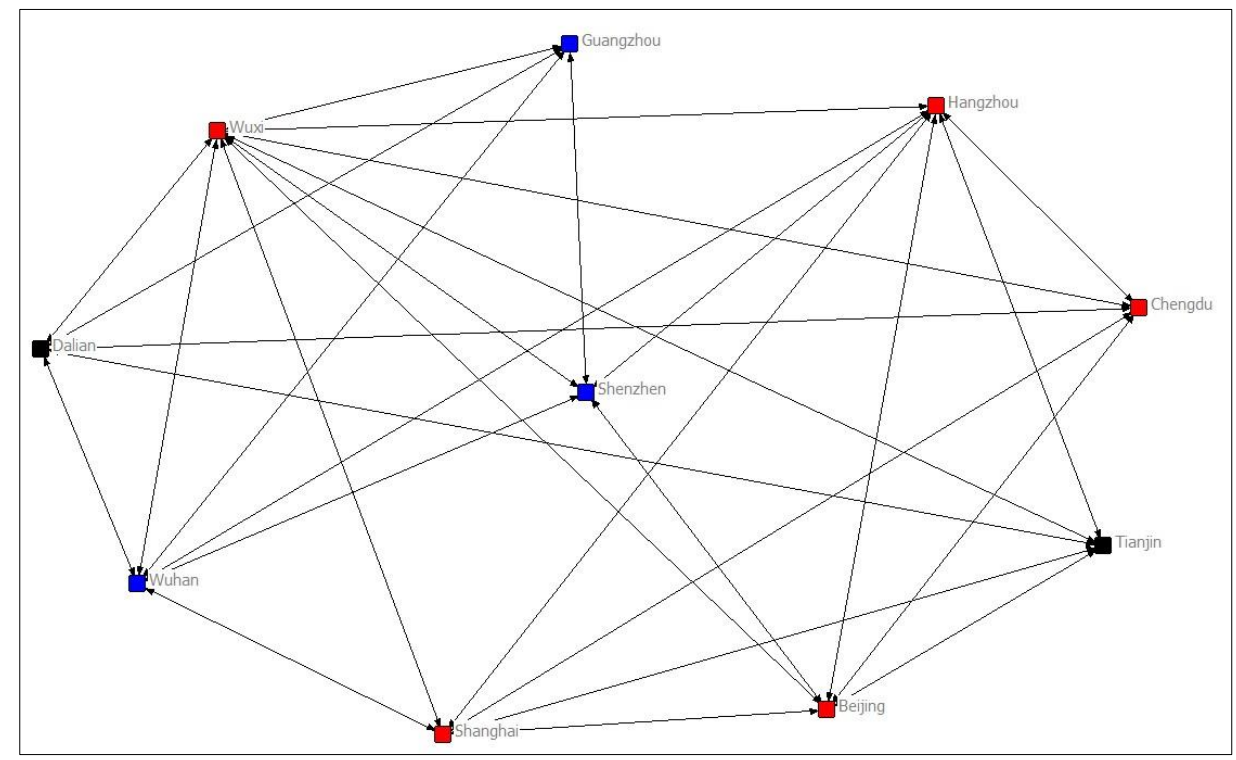

Figure 4. Smart city cluster network: 2005-2007.

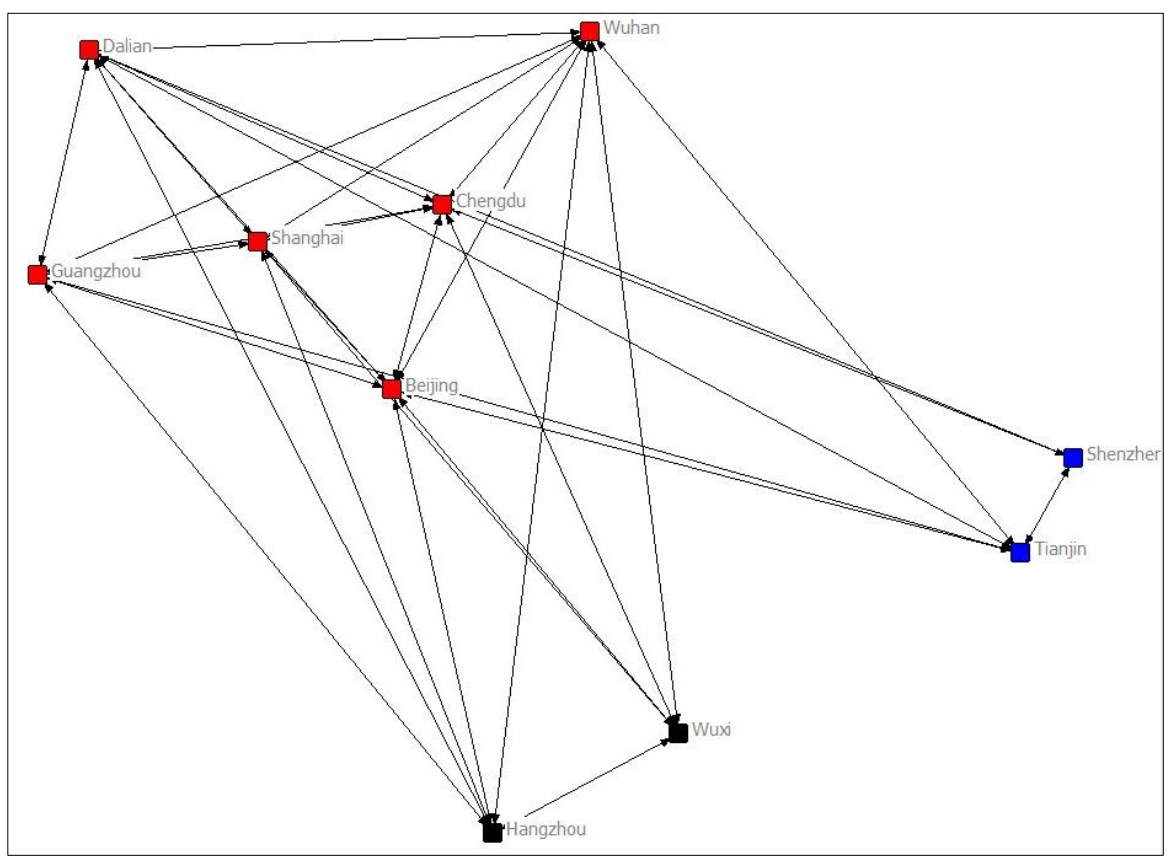

Figure 5. Smart city cluster network: 2008-2010. 


\section{Conclusions and Recommendation}

A smart city is a place with both knowledge orientation and cultural diversity. In this study, we conduct both a space-time analysis and a social network analysis for discussing the relative positions and mutual influences of the smart cities in China. We discuss the city performance over a period of time that ranges from 2005 to 2010, and examined both the position in each point of time and the movement year by year. This research is based on five dimensions: communication, business, human capital, environment and public services, which are universal benchmarking perspectives. The indicators within each dimension are selected by considering the special conditions in China, based on which, the different performance of the ten selected cities are found. Finally, we discussed the smart city cluster network in China. The changes of the cluster network in different stages are presented, which is an improvement compared to previous studies on smart city performance. According to the SOM mapping and subgroup analysis, more smart cities in China have become similar to Beijing or Shanghai during 2005-2010, which shows the demonstration effects of the leading cities. The reason behind this result can be attributed to the significant top-down driven governance model in China: once a pilot city is select, other cities are supposed to follow the development pattern of the pilot city. The governance model could achieve rapid results in the short term. However, it could make thousands of cities with the same image in the long term. In fact, this phenomenon has occurred. It could be dangerous to treat smart city development as a movement. Moreover, public participation should be strengthened in China as human-city interaction is the core of a smart city.

In the future, more smart city characteristics should be taken into account, not only because of the fast-increasing "smart" features, but also the fact that knowledge resulting from city development change is a complex process. Many factors will be involved in this process and affect the social network analysis. The diffusion effect of smart cities among small communities will also be a possible future research agenda.

\section{Acknowledgments}

This work was supported by Macau Foundation, the Faculty Research Grant of Macau University of Science and Technology and Macao Polytechnic Institute（RP/OTHER-01/2014）.

\section{Author Contributions}

This research was designed and written by Dong Lu, Ye Tian, Vincent Y. Liu, Yi Zhang. Every author made an equal contribution to this research. The data was analyzed by Vincent Y. Liu and the data analysis is corresponding to Vincent Y. Liu as well. All authors approved the final manuscript.

\section{Conflicts of Interest}

The authors declare no conflict of interest.

\section{References}

1. Dodgson, M.; Gann, D. Technological innovation and complex systems in cities. Urban Tech. 2011, $18,101-103$. 
2. Arribas-Bela, D.; Kourtit, K.; Nijkamp, P. Benchmarking of world cities through self-organizing maps. Cities 2013, 31, 248-257.

3. Kourtit, K.; Nijkamp, P.; Arribas, D. Smart cities in perspective-A comparative European study by means of self-organizing maps. Innovation (Abingdon) 2012, 25, 229-246.

4. Lombardi, P. Modeling the smart city performance. Innovation (Abingdon) 2012, 25, 137-149.

5. Komninos, N. Intelligent Cities and Globalization of Innovation Networks; Routledge: Oxford, UK, 2008.

6. Florida, R. The world is spiky. Atl. Mon. 2005, 296, 48-51.

7. Carrillo, F.J. Knowledge Cities; Elsevier: Oxford, UK, 2006.

8. Tranos, E.; Gertner, D. Smart networked cities? Innovation (Abingdon) 2012, 25, 175-190.

9. Shapiro, J.M. Smart cities: quality of life, productivity, and the growth effects of human capital. Rev. Econ. Stat. 2008, 88, 324-335.

10. Torres, L.; Pina, V.; Acerete, B. E-government developments on delivering public services among EU. Cities. Gov. Inf. Q. 2005, 22, 217-238.

11. Yovanof, G.S.; Hazapis, G.N. An architectural framework and enabling wireless technologies for digital cities \& intelligent urban environments. Wireless Pers. Commun. 2009, 49, 445-463.

12. Benner, C. Learning communities in a learning region: The soft infrastructure of cross firm learning networks. Environ. Plann. A 2003, 35, 1809-1830.

13. Caragliu, A. Smart cities in Europe. J. Urban Technol. 2011, 18, 65-82.

14. Belissent, J. Getting Clever about Smart Cities: New Opportunities Require New Business Models; Forrester Research, Inc.: Cambridge, MA, USA, 2010.

15. Yide, L. Wireless sensor network applications in smart grid: Recent trends and challenges. Int. J. Distrib. S. N. 2012, 2012, Article 492819.

16. Zapater, M.; Sanchez, C.; Ayala, J.L.; Moya, J.M.; Risco-Martín, J.L. Ubiquitous green computing techniques for high demand applications in smart environments. Sensors 2012, 12, 659-677.

17. Watteyne, T.; Pister, K.S.J. Smarter cities through standards-based wireless sensor networks. IBM J. Res. Dev. 2011, 55, 7:1-7:10.

18. Lazaroiu, G.C.; Roscia, M. Definition methodology for the smart cities model. Energy 2012, 47, 326-332.

19. Allwinkle, S.; Cruickshank, P. Creating smarter cities: an overview. J. Urban Technol. 2011, 18, 1-16.

20. Chatzigiannakis, I.; Fischer, S.; Koninis, C.; Mylonas, G.; Pfisterer, D. WISEBED: An open large-scale wireless sensor network testbed. In Proceedings of the 1st International Conference on SENSAPPEAL 2009, Athens, Greece, 25 September 2009.

21. Sanchez, L.; Galache, J.A.; Gutierrez, V.; Hernandez, J.M.; Bernat, J.; Gluhak, A.; Garcia, T. SmartSantander: The meeting point between future internet research and experimentation and the smart cities. In Proceedings of the Future Network Mobile Summit, Warsaw, Poland, 15-17 June 2011.

22. Holland, G. Will the real smart city please stand up? Cities 2008, 12, 303-320.

23. Lee, S.M.; Tan, X.; Trimi, S. Current practices of leading e-government countries. Commun. ACM 2006, 48, 100-104.

24. Hancke, G.P.; Hancke, G.P., Jr.; The role of advanced sensing in smart cities. Sensors 2013, 13, 393-425.

25. Paskaleva, K. Assessing local e-governance in Europe. IJEGR 2008, 4, 17-36. 
26. Kohonen, T. Self-Organizing Maps, 3rd ed.; Springer: Berlin, Germany, 2001.

27. Behan, K. Smart growth strategies, transportation and urban sprawl: simulated futures for Hamilton, Ontario. Can. Geogr-Geogr. Can. 2008, 52, 291-308.

28. Berelowitz, L. Dream City: Vancouver and the Global Imagination, Douglas \& McIntyre: Vancouver, Canada, 2005.

29. Portney, K. Civic engagement and sustainable cities in the United States. Public Admin. Rev. 2005, 65, 579-591.

30. Debnath, A.; Haque, M.; Chin, H.; Yuen, B. Sustainable urban transport: smart technology initiatives in Singapore. Transport Res. Rec. 2011, 2243, 38-45.

31. William, D.G. North American-type smart growth and the Japanese Suburb: A case study. J. Asian Archit. Build 2007, 6, 95-101.

32. Hollands, R. Will the real smart city stand up? Creative, progressive, or just entrepreneurial? City 2008, 12, 302-320.

33. Song, J.H. IT839 policy leading to u-Korea. In Proceedings of the 32nd International Conference on Very Large Data Bases, Seoul, Korea, 1 September 2006.

34. Ministry of Housing in China. The Pilot Smart City List. Available online: http://www.mgov.cn/complexity/info1308.htm (accessed on 10 June 2015).

35. Caragliu, A.; Bo, C.D. Smartness and European urban performance: Assessing the local impacts of smart urban attributes. Innovation (Abingdon) 2012, 25, 97-113.

36. Méndez, R.; Moral, S.S. Spanish cities in the knowledge economy: Theoretical debates and empirical evidence. Eur. Urban Reg. Stud. 2011, 18, 136-155.

37. Chourabi, H.; Nam, T.; Walker, S.; Gil-Garcia, J.R.; Mellouli, S.; Nahon, K.; Pardo, T.A.; Scholl, H.J. Understanding smart cities: An integrative framework. In Proceedings of the 45th Hawaii International Conference on System Sciences, Maui, HI, USA, 4-7 January, 2012.

38. Mattoni, B.; Gugliermetti, F.; Bisegna, F. A multilevel method to assess and design the renovation and integration of Smart Cities. SCS 2015, 15, 105-119.

39. Kohonen, T.; Honkela, T. Kohonen network. Scholarpedia 2007, 2, 1568.

40. Florida, R. The economic geography of talent. Ann. Assoc. Am. Geog. 2002, 92, 743-755.

41. Kiang, M.Y.; Hu, M.Y.; Fisher, D.M. An extended self-organizing map network for market segmentation: A telecommunication example. Decis. Support Syst. 2006, 42, 36-47.

42. Arribas-Bel, D.; Schmidt, C.R. Self-organizing maps and the US urban spatial structure. Environ. Plann. B 2013, 40, 362-371.

43. Leinonen, L.; Hiltunen, T.; Torkkola, K.; Kangas, J. Self-organized acoustic feature map in detection of fricative-vowel co-articulation. J. Acoust. Soc. Am. 1993, 93, 3468-3474.

44. Delbimbo, A.; Landi, L.; Santini, S. Three-dimensional planar-faced object classification with Kohonen maps. Opt. Eng. 1993, 32, 1222-1234.

45. Sabourin, M.; Mitiche, A. Modeling and classification of shape using a Kohonen associative memory with selective multiresolution. Neural Networks 1993, 6, 275-283.

46. Walter, J.A.; Schulten, K.J. Implementation of self-organizing neural networks for visuo-motor control of an industrial robot. IEEE Trans. Neural Networks 1993, 4, 86-95.

47. Skupin, A.; Hagelman, R. Visualizing demographic trajectories with self-organizing maps. GeoInformatica 2005, 9. 159-179. 
48. Chen, N.H.; Huang, S.C.T.; Shu, S.T.; Wang, T.S. Market segmentation, service quality, and overall satisfaction: Self-organizing map and structural equation modeling methods. Qual. Quant. 2013, 2, 969-987.

49. Séverin, E. Self organizing maps in corporate finance: Quantitative and qualitative analysis of debt and leasing. Neurocomputing 2010, 73, 2061-2067.

50. Serrano-Cinca, C. Self organizing neural networks for financial diagnosis. Decis. Support Syst. 1996, 17, 227-238.

51. Linton, J.D.; Himel, M.; Embrechts, M.J. Mapping the structure of research: Business and management as an exemplar. Serials. Rev. 2009, 35, 218-227.

52. Lucchini, M.; Assi, J. Mapping patterns of multiple deprivation and well-being using self-organizing maps: An application to Swiss household panel data. Soc. Indic. Res. 2013, 112, 129-149.

53. Pisati, M.; Whelan, C. T.; Lucchini, M.; Maître, B. Mapping patterns of multiple deprivation using self-organising maps: An application to EU-SILC data for Ireland. Soc. Indic. Res. 2010, 39, 405-418.

54. The Yearbook of Chinese Cities (2005-2010). Available online: http://tongji.cnki.net/ (accessed on 10 June 2015). (In Chinese)

55. Beijing Guomai Internet Information Consulting Co. Ltd. The Smart City Evaluation Report. Available online: http://www.im2m.com.cn/zt/29/ (accessed on 10 June 2015).

56. Naphade, M.;Banavar, G.; Harrison, C.;Paraszczak, J.; Morris, R.Smarter cities and their innovation challenges. Computer 2011, 44, 32-39.

57. Komninos, N. The architecture of intelligent cities. In Proceedings of the 2nd IET International Conference on Intelligent Environments, Athens, Greece, 5-6 July 2006.

(C) 2015 by the authors; licensee MDPI, Basel, Switzerland. This article is an open access article distributed under the terms and conditions of the Creative Commons Attribution license (http://creativecommons.org/licenses/by/4.0/). 